\title{
Antigenic and biochemical study of PKX, the myxosporean causative agent of proliferative kidney disease of salmonid fish
}

\author{
Denis Saulnier, Pierre de Kinkelin* \\ Unité de Virologie et Immunologie Moléculaires, INRA, F-78352 Jouy-en-Josas cedex, France
}

\begin{abstract}
This work aimed at developing techniques to enable further investigations on the epidemiology and immunology of proliferative kidney disease (PKD) and of its causative agent, PKX, a probable myxosporean parasite. An improved PKX cell concentration technique resulted in preparation of an enruched proliferative kidney cell (EPKC) antigen (Ag) that offered a suitable material for rabbit and mouse immunizations, electrophoretical analysis and antigenicity studies of parasitic materials. Rabbit sera and a panel of 11 monoclonal antibodies (MAbs) specific for PKX were obtained. They reacted in ELISA, immunofluorescence tests, immunohistochemistry, immunodot blot and Western blot with EPKC Ag, live or fixed parasitic cells and infected kidney extracts, depending on the Abs and immunological test used. These MAbs were divided into 4 groups according to their reactivity in the above tests and led to the study of the possible localization of putative epitopes on parasite cells. At least 4 major parasitic proteins were visualized by SDS.PAGE electrophoresis and a fifth one, with a relative mobility of $13 \mathrm{kDa}$, was immunostained in Western blot by at least 2 MAbs and rabbit antiserum. The membrane fluorescence reactivity of the epitope suggested this protein was external and could be of immunological importance. The antigenicity detected by histoimmunochemistry was that of primary cells and was apparently specific for PKX since the screening of kidney tissue of 9 nonsalmonid fish species harbouring developmental stages of 3 myxosporean genera remained negative. EPKC Ag was also antigenic for trout undergoing experimental PKD, thus providing evidence for a humoral response to this infection. Our investigations result in the establishment of a novel set of immunological probes suitable for monitoring the course of PKD, checking antigenicity of actinosporeans, purifying parasitic proteins and screening a PKX expression library.
\end{abstract}

KEY WORDS: Salmonids PKD · PKX - Myxosporeans Proteins - Antigenicity - Immunity Antibodies

\section{INTRODUCTION}

Proliferative kidney disease (PKD) (Ferguson \& Adair 1977 ) is a hyperplasic disease of the interstitial kidney tissue and to a lesser extent of spleen tissue due to infection by an unclassified histozoic parasite designated PKX (for 'proliferative kidney organism unknown'). The disease causes severe economic losses in many trout farms. The severity of the disease results from impairment of kidney functions, water-salt imbalance and erythropoiesis, generated by strong in-

\footnotetext{
- Addressee for correspondence.

E-mail: kinkelin@biotec.jouy.inra.fr
}

flammatory response due mainly to macrophages (MacConnell et al. 1989). This leads to the disappearance of nephrons, clearly visible histologically, and probably of erythroblastic cells (Clifton-Hadley et al. 1987). PKD thus appears to be an immunopathological disease.

In a recent review, Hedrick et al. (1993) point out that, although facets of PKD such as clinical, pathological and ultrastructural studies together with host range and environmental conditions have been extensively documented, there is no practically achievable control method for the condition and almost nothing is known about immunity to PKD and the life cycle of its causative agent. Moreover the precise taxonomic status of this agent has still to be established. 
The early developmental stages of myxosporean parasites of fish belonging to the genus Sphaerospora share similarities with PKX cells (Kent \& Hedrick 1.985, Voronin 1993). The development of PKX into an incomplete myxosporean-like spore has been demonstrated (Kent \& Hedrick 1986) but no mature spores could be recovered from salmonid hosts. This is possibly due to the strong inflammatory response that eliminates PKX cells, making PKX taxonomy unresolved and the role of salmonids as definitive hosts questionable.

A lack of suitable investigation techniques could account for the shortage of knowledge on PKD. For this reason, probes for PKX have been developed recently. Griffonia simplicifolia 1 (GSI) lectin, which recognizes methyl $\alpha$-D-galactopyranoside on PKX glycoconjugates (Castagnaro et al. 1991), and a monoclonal antibody (MAb) (Adams et al. 1992) have been used to identify the PKD agent in the form of PKX cells in tissues from salmonid hosts in particular rainbow trout Oncorhynchus mykiss, chinook salmon O. tshawytscha, coho salmon O. kisutch, brown trout Salmo trutta and Atlantic salmon S. salar (Marin de Mateo et al. 1993). However, neither GSI lectin nor the MAb reacted with any developmental stage of cyprinid or trout Sphaerospora (Hedrick et al. 1993). No potential relatedness between PKX and other fish myxosporeans could be demonstrated using standard immunostaining techniques or experimental infection trials (D'Silva et al. 1984, Foot \& Hedrick 1987).

We thus decided to prepare a novel panel of immunological probes before undertaking more accurate investigations on PKD. This paper describes a new method for preparation of enriched PKX cell suspensions that enables both protein studies and immunization of rabbits and mice for raising polyclonal and monoclonal antibodies (Abs). PKX cells and parasitic protein bands were recognised by these Abs using enzyme linked immunosorbent assay (ELISA), indirect immunofluorescence (IF) tests, immunohistochemistry, immunodot blotting and Western blotting.

\section{MATERIALS AND METHODS}

Fish. Specific-pathogen-free rainbow trout originating from the trout farm of INRA's Fish Genetics Laboratory were reared in a recirculating water system at the fish experimental facilities of the research centre at Jouy-en-Josas, France. Depending on experimental needs and seasons, the individual weight of fish used ranged from 50 to $200 \mathrm{~g}$. The fish were kept in $300 \mathrm{l}$ plastic tanks supplied with filtered and ultra-violetdisinfected water at 10 to $12^{\circ} \mathrm{C}$ for maintenance and at $16^{\circ} \mathrm{C}$ for infection trials. Fish were fed dry pellets (Bio- mar, Nersac, France) and the diet was adjusted to obtain a slow growth. Prior to any handling fish were anaesthetized by immersion in a $0.03 \%$ aqueous solution of 2-phenoxyethanol (Prolabo, Paris, France).

Infection trials with PKD. PKX cells were produced by either experimental or natural infections of fish. Experimental infection was achieved by intraperitoneal injection of pathogen-free trout with kidney cell suspensions from PKX-infected trout (D'Silva et al. 1984). The average infecting dose was 500 to $1000 \mathrm{PKX}$ cells per $100 \mathrm{~g}$ trout. Two to four months post-infection, the fish were bled, sacrificed by decapitation and necropsied. All kidneys with a score for hypertrophy $>2$ (Clifton-Hadley et al. 1987) were excised. PKD was thus maintained throughout the year.

Preparation of enriched PKX cell (EPKC) suspensions. PKX-infected kidney tissue from a sacrified rainbow trout displaying a hyperplasic score $>3$ was incubated at $14^{\circ} \mathrm{C}$ for 16 to $20 \mathrm{~h}$ in Stoker's medium supplemented with $100 \mathrm{IU} \mathrm{ml}^{-1}$ of penicillin and $100 \mathrm{mg} \mathrm{ml}^{-1}$ of streptomycin. The infected tissue was then cut into small pieces, and squeezed through a $150 \mu \mathrm{m}$ stainless steel mesh. using a pestle. Cells from one kidney were suspended in a volume of $30 \mathrm{ml}$ of medium and centrifuged for $3 \mathrm{~min}$ at $400 \times \mathrm{g}$ at room temperature. The supernatant was discarded and the pellet resuspended in approximately $30 \mathrm{ml}$ of phosphate-buffered saline (PBS). Large clumps of tissue and cell debris were allowed to settle for about $1 \mathrm{~min}$ and then pipetted off. Two to four successive rounds of centrifugation-resuspension steps were necessary to reach an acceptable degree of PKX cell purity as determined by light microscopy. Parasitic cells were then enumerated using a Malassez hemocytometer and the percentage of PKX cells in the kidney cell suspension estimated.

PKX antigen (Ag) preparation. Cell suspensions containing 50 to $90 \%$ of $\mathrm{PKX}$ cells were pelleted by centrifugation. About $1 \times 10^{7}$ to $1 \times 10^{8} \mathrm{PKX}$ cells were resuspended in $1 \mathrm{ml}$ of $\mathrm{PBS}$ containing protease inhibitors [250 $\mathrm{M} \mathrm{N}$ N-tosyl-L-phenylalanine chloromethyl ketone (TPCK), $100 \mu \mathrm{M} \mathrm{N}-\alpha$-p-tosyl-L-lysine chloromethyl ketone (TLCK), $1 \mathrm{mM}$ phenylmethyl sulphonyl fluoride (PMSF, Boehringer) ]. Parasites were sonicated on ice for 1 min using an OSI $100 \mathrm{~W}$ sonicator with a $3 \mathrm{~mm}$ probe at an amplitude of $18 \mu \mathrm{m}$ peak to peak, and centrifuged at $10000 \times g$ for $3 \mathrm{~min}$. The proteins in the supernatant were quantified by a Bradford protein assay (Bradford 1976) according to the manufacturer (Bio-Rad Lab., Richmond, CA, USA) and used for immunizations and ELISA procedure screening. For protein andysis by sodium dodecyl sulfate polyacrylamide gel electophoresis (SDS-PAGE) or Western blotting, pelleted PKX cells were resuspended in a lysis buffer containing $1 \%$ Triton X100. Control. anti- 
gen for ELISA and SDS-PAGE was extracted from normal kidney cells (NKC) of uninfected rainbow trout and quantified by the same protein assay as above.

Rabbit immunization and serum processing. Two New Zealand white rabbits (INRA's rodent animal facility) each received $1 \mathrm{mg}$ of EPKC Ag in $1 \mathrm{ml}$ of a $\mathrm{v} / \mathrm{v}$ emulsion in Freund's adjuvant, delivered as 2 series of 40 intradermal injections (20 per body side) performed at a 21 d interval. Freund's complete adjuvant (FCA) was used for primary injection and Freund's incomplete adjuvant (FIA) for booster injection. The rabbits were bled 3 wk after booster injection, and sera were heat-inactivated at $56^{\circ} \mathrm{C}$ for $30 \mathrm{~min}$, filtered through $220 \mu \mathrm{m}$ membranes (Minisart NML Sartorius, Göttingen, Germany) and stored either at $4^{\circ} \mathrm{C}$ or frozen at $-20^{\circ} \mathrm{C}$. Prior to use, the sera were in vivo adsorbed by intraperitoneal injection to pathogen-free rainbow trout and further recovered after $18 \mathrm{~h}$ post-injection (P. E. Vestergaard-Jørgensen \& N. Olesen unpubl.). The reactivity of rabbit sera was studied using IF test, ELISA and Western blotting (see below).

Inmunization of mice. Two-month-old Balb $\mathrm{C}$ female mice were immunized according to 2 protocols.

In the first protocol, $100 \mu \mathrm{g}$ of EPKC antigen diluted in PBS was emulsified with FCA $1: 1(\mathrm{v} / \mathrm{v})$ and injected intraperitoneally into one mouse in a volume of $400 \mu \mathrm{l}$. Four mice were successively immunized. Depending on the mice, 2 to 5 repeated injections were performed at 7 to $12 \mathrm{~d}$ intervals. Mouse antisera were tested by IF technique performed on PKX-infected trout kidney imprints and by ELISA test on EPKC and NKC antigens. The mouse that expressed the higher titer of specific antibodies was sacrificed for further fusion.

In the second protocol, 1 mouse was hind foot padimmunized with 2 repeated injections of $25 \mu \mathrm{g}$ of the same antigen preparation performed at 2 wk intervals.

Fusions with SP2/O non-secreting tumor cells line were achieved $4 \mathrm{~d}$ after the last booster injection with lymphocytes collected either from the spleen or from poplietal nodes, according to the procedure described by Kohler \& Milstein (1975). After approximately $10 \mathrm{~d}$, hybridoma culture supernatants were screened by IF test on infected kidney imprints and ELISA on both EPKC and NKC Ags. Polyclonal and preimmune sera were used for positive and negative controls respectively. The immunoglobulin (Ig) classes and subclasses secreted by hybridomas were determined by ELISA (Ab-Stat-I, SangStat Medical Co., CA, USA).

Cloning, ascites production and MAb purification. Hybridoma cell lines were cloned by limiting dilution in order to obtain 0.5 cell per well. Ascitic fluids were generated from pristane-primed BalbC mice by the injection of $1 \times 10^{7}$ tumor cells. Immunoglobulins were precipitated by water-saturated ammonium sulphate mixed $1: 1(\mathrm{v} / \mathrm{v})$ with ascitic fluid and dialyzed against PBS.
Enzyme linked immunosorbent assay (ELISA). ELISA was used to screen both the response of rabbits and mice after immunization and the antigenicity of EPKC Ag for rabbit sera, mouse MAbs and PKXinfected trout sera.

ELISA for detection of mammalian Abs: Microtiter plates (Nunc, Immunoplate, Denmark) were coated with $300 \mathrm{ng}$ of EPKC and NKC antigens per well in PBS (0.01M, pH 7.3) and incubated overnight at $4^{\circ} \mathrm{C}$. Unbound material was removed after each incubation step by washing the plates 3 times with PBS containing $0.05 \%$ Tween 20 (PBST). Polyclonal Abs diluted in PBS supplemented with $3 \%$ bovine serum albumin (BSA) or crude hybridoma supernatants were incubated for $1 \mathrm{~h}$ at $37^{\circ} \mathrm{C}$ and further revealed by a rabbit anti-mouse or a goat anti-rabbit IgG $(\mathrm{H}+\mathrm{L})$ conjugated with alkaline phosphatase (Biosys, Compiègne, France). Nitrophenol phosphate (pNPP, Pierce, Rockford, IL, USA) was used as substrate and the optical density (OD) spectrophotometrically read at $405 \mathrm{~nm}$. Results are expressed as the difference between $O D$ in the presence of antibody and OD obtained with BSA.

ELISA for detection of trout Abs: Plates were coated with $2 \mu \mathrm{g}$ per well of EPKC antigen and treated for $2 \mathrm{~h}$ at $22^{\circ} \mathrm{C}$ with sera from normal or PKX-infected rainbow trout, diluted $1: 10,1: 50$ and $1: 250$ in PBS supplemented with $2 \%$ skim milk. The plates were then washed 3 times with PBST and treated for $1 \mathrm{~h}$ at $22^{\circ} \mathrm{C}$ with MAb I.14 (DeLuca et al. 1983) in the form of ascitic fluid diluted 1:20000 in PBS plus 2\% skim milk. After 3 additional washing steps with PBST, the binding of mouse MAb I.14 was revealed using the same conjugate as above. The value of OD was assessed using skim milk instead of BSA as was done for mammalian $\mathrm{Ab}$ detection.

Immunodot blotting of PKX antigens. Rainbow trout kidney samples were excised, transferred into $1.5 \mathrm{ml}$ plastic tubes (Eppendorf, Hamburg, Germany), weighed and further ground in the same tubes with an appropriate conic pestle. The resulting materials were resuspended in Tris buffered saline (TBS: Tris-HCl $50 \mathrm{mM}, \mathrm{pH} 7.4, \mathrm{NaCl} 200 \mathrm{mM}$. Volumes of buffer were adjusted in order to obtain a final concentration of $100 \mu \mathrm{g}$ of tissue per $\mathrm{ml}$ of TBS. Kidney homogenates were sedimented for $10 \mathrm{~min}$ at $3500 \times g$ and supernatants collected. Protein concentration of the supernatant was determined according to Bradford (1976) at wavelength $595 \mathrm{~nm}$.

The dot blot was prepared according to Hawkes et al. (1982). The membrane (Problott Membranes, Applied Biosystem, CA, USA) was cut to a suitable size, dipped in methanol for $5 \mathrm{~s}$, rinsed in distilled water, then in TBS and placed into the dot blot apparatus (Bio Rad, Richmond CA, USA). One hundred microliters of 2-fold step dilutions of EPKC or NKC Ags 
(30 to $3.75 \mu \mathrm{g}$ per $\mathrm{ml}$ of proteins) were applied. Identical volumes of homogenate supernatants from crude PKX-infected or uninfected kidney extracts were put onto the membrane (500 to $4000 \mu \mathrm{g}$ proteins $\mathrm{ml}^{-1}$ ). The dot blot apparatus was then placed at $4^{\circ} \mathrm{C}$ for 10 min and the membrane rinsed with TBS under vacuum. The membrane was then recovered from the apparatus and blocked for $1 \mathrm{~h}$ with $3 \%$ BSA-TBS under gentle swinging at room temperature. The membrane was then cut into strips and incubated for $2 \mathrm{~h}$ with hybridoma supernatants or in vivo absorbed rabbit serum (RAs) diluted in 3\% BSA-TBS. After three 5 min rinses the strips were incubated for $1 \mathrm{~h}$ with the same conjugates as for ELISA. Following 3 more rinses, blots were stained using nitroblue tetrazolium and bromochloro-indolylphosphate toluidine salt chromogens (NTB-BCIP, Gibco BRL, Life Technologies Inc., Gaithersburg, MD, USA) diluted in Tris-buffered saline (Tris HCl $100 \mathrm{mM}$, pH 9.5, $\mathrm{NaCl} 100 \mathrm{mM}, \mathrm{MgCl}_{2} 50 \mathrm{mM}$ ). Development was stopped by immersing the blots for 5 min in distilled water; blots were then placed between 2 sheets of filter paper and dried in the dark

Indirect immunofluorescence test. PKX-infected trout kidney imprints previously fixed in absolute ethanol/acetone $30: 70$ at $-20^{\circ} \mathrm{C}$ were incubated for 45 min at $37^{\circ} \mathrm{C}$ with monoclonal or polyclonal $\mathrm{Abs}$. $\mathrm{Ab}$ binding was detected using a sheep anti-mouse IgG $(\mathrm{H}+\mathrm{L})$ or a goat anti-rabbit $\operatorname{Ig} \mathrm{G}(\mathrm{H}+\mathrm{L})$ conjugated with fluorescein isothiocyanate (FITC, Biosys, Compiègne). Some immunofluorescence tests were also conducted on live and $4 \%$ paraformaldehyde (PF) fixed PKX cells. Specificity of positive hybridoma culture supernatants for PKX cells was assessed by a double labelling fluorescence method (Marin de Mateo et al. 1993). Kidney imprints were incubated simultaneously with undiluted supernatants and biotinylated Griffonia simplicifolia lectin (GSI) used at $30 \mathrm{mg} \mathrm{m}^{-1}$ (GSI, Sigma L-3759, St Louis, MO, USA). Antibodies and lectin were then revealed with. FITC and rhodamineavidine (Vector Laboratories Inc., Burlingame, CA, USA) conjugates. The stained imprint preparations were observed under incident UV light at $400 \times$ with a Laborlux microscope (Leitz, Weitzlar, Germany) fitted with barrier filters for both fluorescein and rhodamine.

Immunohistochemistry. Samples of rainbow trout kidney and sometimes liver were fixed with either Davidson's fixative or $10 \%$ neutral buffered formalin and embedded in paraffin. PKX-infected rainbow trout tissues fixed in Bouin's solution during the past decade were also checked for parasitic antigenicity. For preliminary assessment of the anti-PKX specificity of our Abs, myxosporean-infected kidneys from nonsalmonid fish, sampled by electric fishing in the river water supplies of 2 trout farms where PKD occurs, were collected and fixed in either Davidson's fixative or $10 \%$ neutral formalin. The fish species examined were bleak Albumus alburnus, bream Abramis brama, chub Leuciscus cephalus, sculpin Cottus gobio, gudgeon Gobio gobio, loach Nemacheilus barbatula, minnow Phoxinus phoxinus, roach Rutilus rutilus and seven-spine stickleback Pungitius pungitius. The myxosporean spores observed were species belonging to the genera Myxobolus, Myxidium and Sphaerospora. At least one spore-harbouring kidney from each fish species was tested by immunostaining. Embedded materials were sectioned (5 $\mu \mathrm{m}$ ) deparaffinized and further treated with appropriate dilutions of polyclonal or monoclonal Abs in 3\% BSA-PBS. The PKX cellbound Abs were revealed by a streptavidin-peroxidase conjugate using amino-ethyl-carbazole (AEC) as chromogen and counterstained with hematoxylin, according to manufacturer's specifications (Immunostaining kit, Immunotech, Marseille, France).

Sodium dodecyl sulphate-polyacrylamide gel electrophoresis (SDS-PAGE) and Western-blotting. EPKC and NKC proteins were reduced with 2-mercaptoethanol and separated on 12\% SDS-polyacrylamide gels according to Laemmli (1970). Proteins were then transferred onto polyvinylidene difluoride membrane in cyclohexylamino propanesulfic acid buffer (ProBlott Membranes, Applied Biosystems, CA, USA) by electroblotting (Bio-Rad Lab., Richmond, CA, USA) in cyclohexylamino propanesulfonic acid buffer (CAPS). The membranes were blocked in 3\% BSA-PBS and subsequently cut into strips. Strips were incubated for $1 \mathrm{~h}$ with antibody probe, washed with PBST, and further incubated for $1 \mathrm{~h}$ at room lemperature with the same conjugates as for ELISA. Incubation steps were performed over $1 \mathrm{~h}$ at room temperature and the strips were developed with NBT and BCIP chromogens.

\section{RESULTS}

\section{Enrichment technique for PKX cell suspensions}

Parasitic cell suspensions containing 50 to $90 \%$ of PKX cells were consistently obtained from dispersed infected kidney tissue harbouring, most often, less than $1 \%$ of PKX cells (Fig. 1). The number of PKX cells recovered from individual fish kidneys displaying hypertrophic score $\geq 3$ showed a large range of variation in the parasitic yields obtained (Table 1). Although suitable for antigenic studies, the PKX cells from enriched suspensions lost their infectivity for trout. Indeed, 2 infection trials performed by intraperitoneal injection of $50 \mathrm{~g}$ rainbow trout with PKX cell numbers up to $2 \times 10^{5}$ per fish failed to reproduce PKD. In contrast, control fish that received untreated parasites contracted the parasitic condition. 

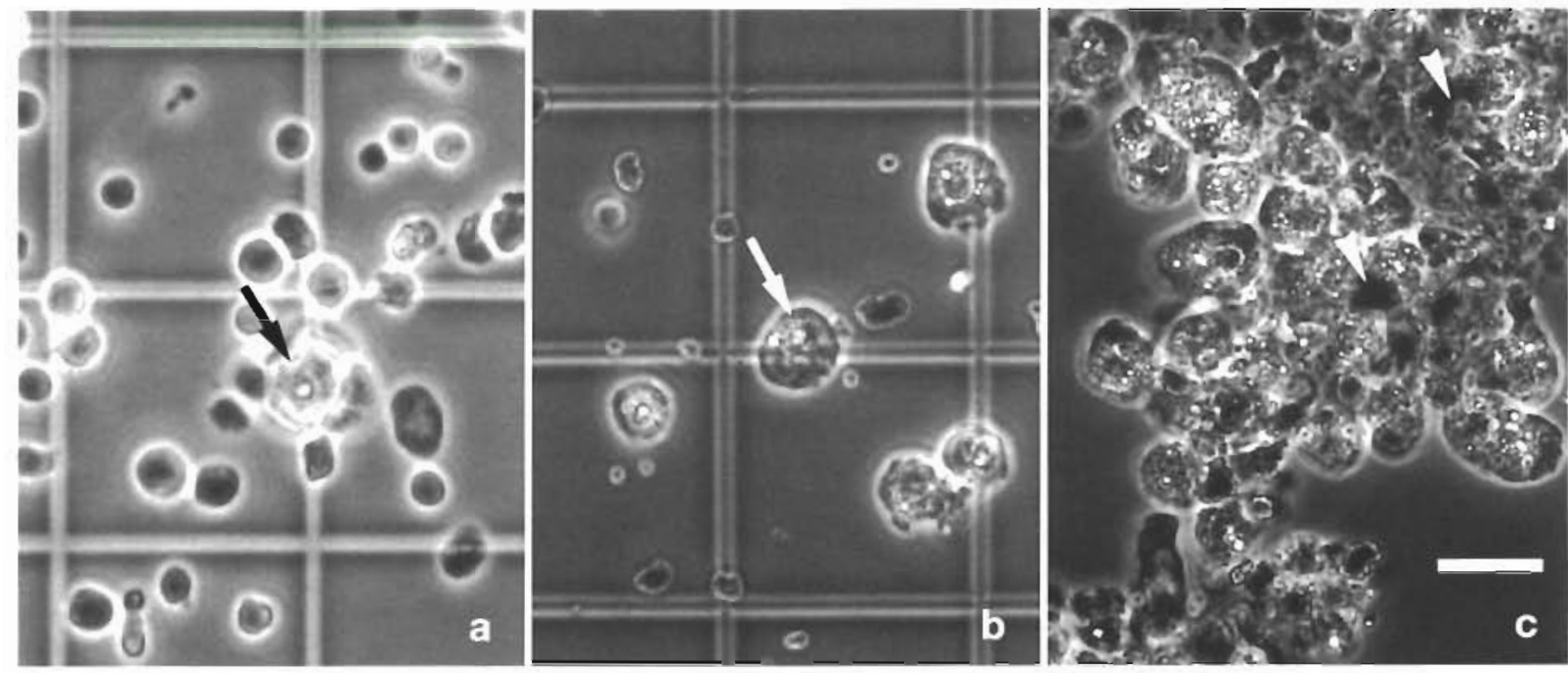

Fig. 1. Enrichment of a PKX cell suspension. (a) Untreated cell suspension: one parasitic cell (arrow) among leucocytes and erythrocytes. (b) PKX cells sampled just after the enrichment procedure; only debris from fish blood cells remains visible. (c) Aggregated PKX cells in the cell suspension intended for the preparation of enriched proliferative kidney celis (EPKC) Ag; some melanomacrophages (arrowheads) are still present. Phase contrast, objective $40 \times$, scale bar $=20 \mu \mathrm{m}$

Table 1 Number of PKX cells recovered from 11 rainbow trout kidneys with hypertrophic score $\geq 3$, by using the enrichment technique $98 \mathrm{~d}$ after the experimental infection of fish

\begin{tabular}{|cc|}
\hline Fish weight $(\mathrm{g})$ & No. of PKX cells $\times 10^{6}$ \\
\hline 14 & 0.2 \\
27 & 7.5 \\
35 & 13 \\
35 & 3.5 \\
39 & 8 \\
44 & 1.4 \\
53 & 16 \\
56 & 1.1 \\
57 & 11 \\
62 & 25 \\
76 & 0.6 \\
\hline
\end{tabular}

\section{Antigenicity of $\mathrm{PKX}$ for immune rabbit sera}

EPKC Ag was fairly immunogenic for rabbit but antigenic studies revealed a noticeable background of reactivity with trout tissue extracts and cells in both ELISA and IF tests. In ELISA, the reactivity of immune serum to NKC Ag was roughly half of that to EPKC Ag (Fig. 2a). The in vivo absorption of rabbit sera (RAs) eliminated this background of reactivity within $18 \mathrm{~h}$ (Fig. 2b). Indeed, even though the rabbit Abs reactivity in trout serum was already PKX Ag specific $3 \mathrm{~h}$ after rabbit serum injection into trout, absorption kinetics demonstrated that this reactivity peaked between 18 and $24 \mathrm{~h}$ post trout injection (not shown). Assuming the blood volume of a $200 \mathrm{~g}$ trout is $10 \mathrm{ml}$, the injection of
Fig. 2. Antigenicity of EPKC Ag for homologous rabbit serum (a) before and (b) after in vivo absorption of rabbit serum in rainbow trout. Absorbance value curves of ELISA performed with EPKC Ag (-) or normal kidney cell (NKC) Ag (..--) coated with respective protein amounts of $100 \mathrm{ng}(\Delta)$, $300 \mathrm{ng}$ (a) and 500 (0) ng per well

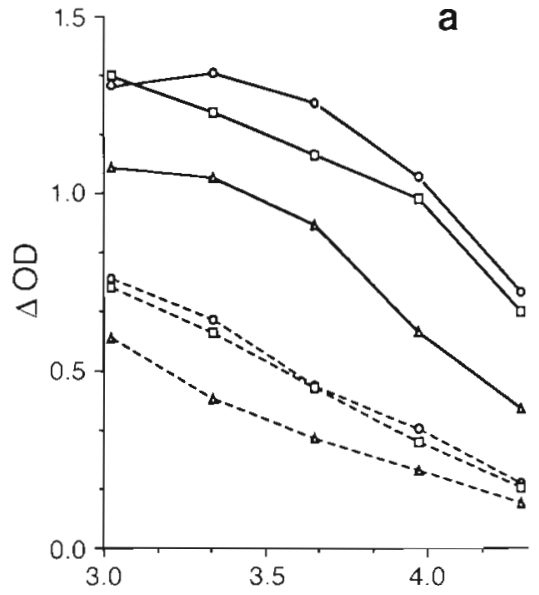

Reciprocal of Log dilution of rabbit serum

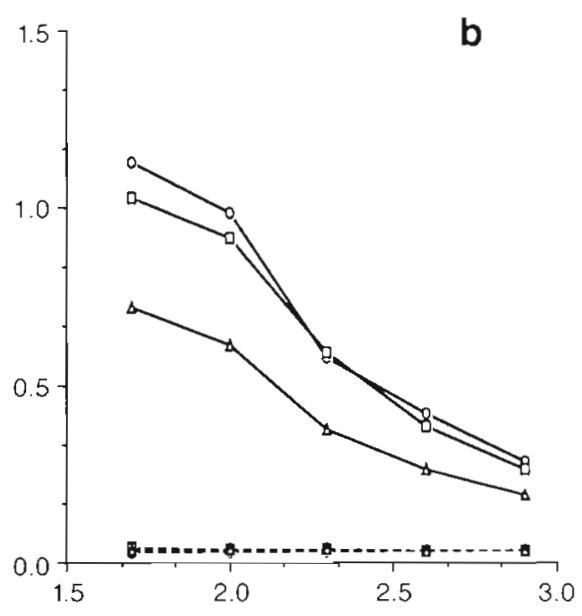

Reciprocal of Log dilution of trout serum 


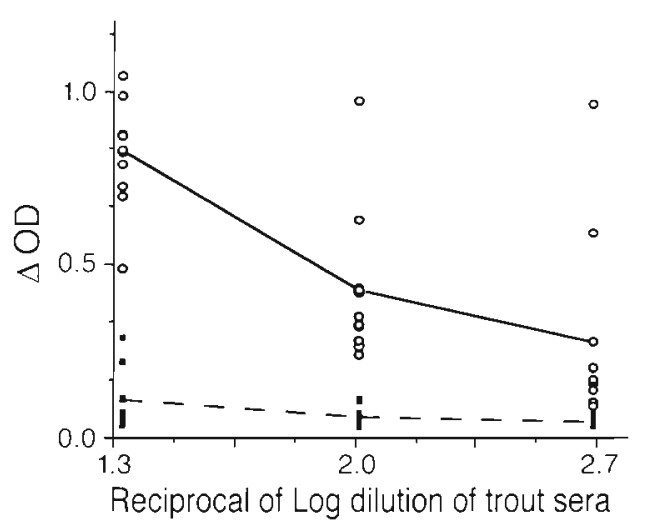

Fig. 3. Antigenicity of PKX for sera from PKX-infected trout Absorbances values of ELISA performed on EPKC Ag $(2 \mu \mathrm{g}$ per well) with 10 rainbow trout sera sampled $60 \mathrm{~d}$ postexperimental infection and 10 sera from non-infected control

Mean positive $(-)$ and negative $(--)$ response curves

$1 \mathrm{ml}$ of rabbit serum corresponds to an Ab dilution of $1: 10$ and when completing ELISA to final dilutions of 1:50 to 1:800. Positive ELISA responses were obtained with the 3 amounts of EPKC Ag tested (100 to $500 \mathrm{ng}$ per well). It appears from Fig. 2 that the gain in the specificity of the Ab detection is balanced by a loss of broad serum reactivity insofar as the detection of $100 \mathrm{ng}$ of EPKC Ag generates an equal absorbance value using native rabbit serum at dilution 1:9000 or RAs (i.e. trout serum) at dilution 1:100. Assuming that the dilution of rabbit serum in trout blood was approximately $1: 10,90 \%$ of the reactivity of native rabbit serum formerly monitored (Fig 2a) was not PKX specific.

\section{Antigenicity of PKX for sera from PKD experimentally infected rainbow trout}

Sera were obtained from 32 PKD-infected rainbow trout and 20 mock-infected controls reared together at $16^{\circ} \mathrm{C}$. The fish were $18 \mathrm{mo}$ old and weighed 100 to $150 \mathrm{~g}$ Sera were collected on Day 59 post infection, diluted 1:20 and screened by ELISA on EPKC Ag. Four- teen sera from infected trout generated absorbance values double those from controls (not shown). Ten sera from each group of fish were then selected, diluted 1:20, 1:100 and 1:500, and retested. All the sera from PKD-infected fish displayed positive responses with a titre of 100 and at least 4 of them at a titre of 500 (Fig. 3).

\section{Monoclonal antibodies: generation and reactivity with PKX}

The best yields from hybridoma positive clones were obtained from fusions performed with popliteal node cells (about $10 \%$ ). Out of 39 clones from 2 series of fusions 11 hybridomas were selected and subcloned on the basis of their higher degree of reactivity in both ELISA and IF assays. Ascitic fluids were raised from mice for MAbs no, 6, 8, 10 and 11 .

The overall characteristics of anti-PKX MAbs are given in Table 2 . They encompass isotype and reactivity in ELISA, IF test, immunostaining, immunodot blotting and Western blotting. Considering the antigenicity of EPKC Ag in ELISA and that of parasitic cells in IF and immunostaining, our MAbs can be placed into 4 groups. Group 1 encompassed MAbs 1, 6, 8 and 10, which reacted positively in ELISA, IF test and immunohistochemistry. Furthermore, MAbs 8 and 10 from this group reacted with EPKC Ag in immunodot blot and Western blot and PKX-infected kidney extracts (IKE) in immunodot blot assays. Group 2 comprised MAbs 3 and 9 , which reacted in ELISA and immunostaining. Group 3 encompassed IF and immunochemistryreactive MAbs 2, 5, and 11. Group 4 comprised MAbs 4 and 7 , which only reacted in IF. Depending on the MAbs used, fluorescence was present in 2 localities cytoplasmic (Fig. 4a) or peripherical (Fig. 5a). The cells that were stained in fluorescence were also recognized by GSI lectin (Fig. $4 \mathrm{~b} \& 5 \mathrm{~b}$ ). Double probing of PKX cells with MAbs and biotinylated lectin resulted in the overlapping of FITC and rhodamine fluorescences (Fig. 4c \& 5c). When the IF test was performed with live or PF-fixed PKX cells, MAbs 7, 8 and 10 clearly

Table 2. Characteristics of monoclonal antibodies against PKX. + : positive reaction; wk: weakly positive reaction; - : negative reaction: nd: not done

\begin{tabular}{|c|c|c|c|c|c|c|c|c|c|c|c|}
\hline & 1 & 2 & 3 & 4 & 5 & $\begin{array}{c}\text { AAb n } \\
6\end{array}$ & 7 & 8 & 9 & 10 & 11 \\
\hline Isotype & $\operatorname{Ig} M$ & $\operatorname{Ig} M$ & $\lg M$ & $\operatorname{Ig} G_{1}$ & $\operatorname{IgG}_{1}$ & $\lg _{1}$ & $\lg G_{1}$ & $\operatorname{IgG}_{3}$ & $\operatorname{Ig} M$ & $\operatorname{IgG} G_{3}$ & $\lg G_{1}$ \\
\hline ELISA & + & - & + & - & - & + & - & + & + & + & - \\
\hline Immunofluorescence & + & + & - & + & + & + & + & + & - & + & + \\
\hline Immunochemistry & + & + & + & - & + & + & - & + & + & + & + \\
\hline Immunodot blotting & + & - & + & - & - & + & - & + & - & + & nd \\
\hline Western blotting & wk & - & $w k$ & - & - & wk & - & + & - & + & - \\
\hline
\end{tabular}


Figs. 4 \& 5. Antigenicity of ethanolacetone-fixed PKX cells in rainbow trout kidney imprints for MAbs as studied by indirect immunofluorescence test. Two aspects of fluorescence are presented. Fig. 4. Cytoplasmic fluorescence (a) Immunostaining with MAb 11 revealed with FITC labelled goat anti-mouse $\mathrm{IgG}_{\text {; }}$ (b) staining of the same PKX cells with biotinylated GSI lectin revealed with avidine-conjugated rhodamine; (c) double staining (MAb-FITC and GSI lectin-rhodamine) showing the overlaping of the 2 stains in same cells. Objective lens $40 x$, scale bar $=$ $20 \mu \mathrm{m}$. Fig. 5. Peripherical fluorescence revealed as above. (a) Immunostaining with MAb 10 ; (b) staining with GS-1 lectin; (c) double staining. Scale bar = $20 \mu \mathrm{m}$
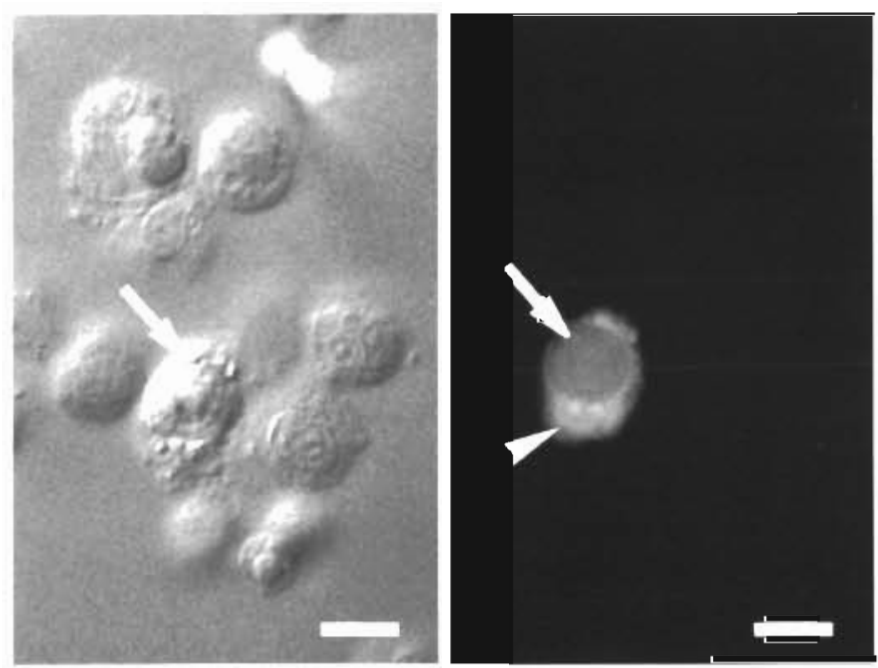

Fig. 6. Antigenicity of PKX cells fixed with $4 \%$ paraformaldehyde for MAbs by indirect immunofluorescence test. (a) Interferential phase contrast microscopic examination of the cell suspension; PKX cell is arrowed (DRMB photomicroscope Leitz, Weitzlar Germany, Objective lens $40 \times$ ); (b) view of the cell after probing with MAb 10, which generates membrane fluorescence (arrowhead). Scale bar $=20 \mu \mathrm{m}$
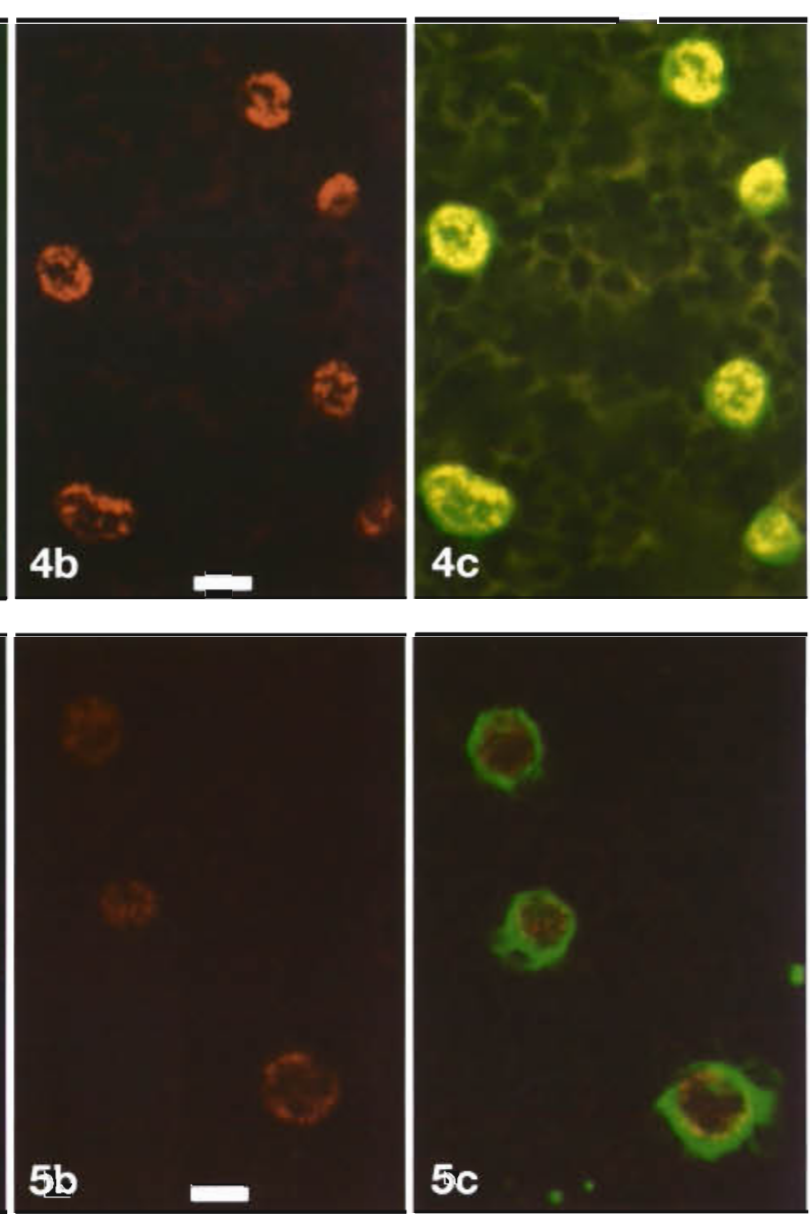

appeared to react with epitope(s) located in the cell plasmalemma (Fig. 6) whereas MAbs 1, 2, 4, 5,6 and 11 failed to react. Furthermore, not all PKX cells displayed this membrane fluorescence (not shown).

\section{Antigenicity of histologically processed PKX cells}

The PKX cells harboured in tissues from PKD. infected rainbow trout reacted positively to an immunoperoxidase test performed with RAs or MAbs, with the exception of MAbs 4 and 7 . Both intraluminal and extrasporogonic stages in kidney were stained by AEC on primary cells but not on daughter cells, regardless of the $\mathrm{Ab}$ used (Fig. 7). The parasitic cells were found in all previously known sites (spleen, liver, pancreas, blood) and even in an unusual site such as the mucosa of the ascending intestine (Fig. 8). After the MAbs were individually tested with PKX cells, the hybridoma culture supernatants that reacted positively were pooled and used to check possible antigenicity of 


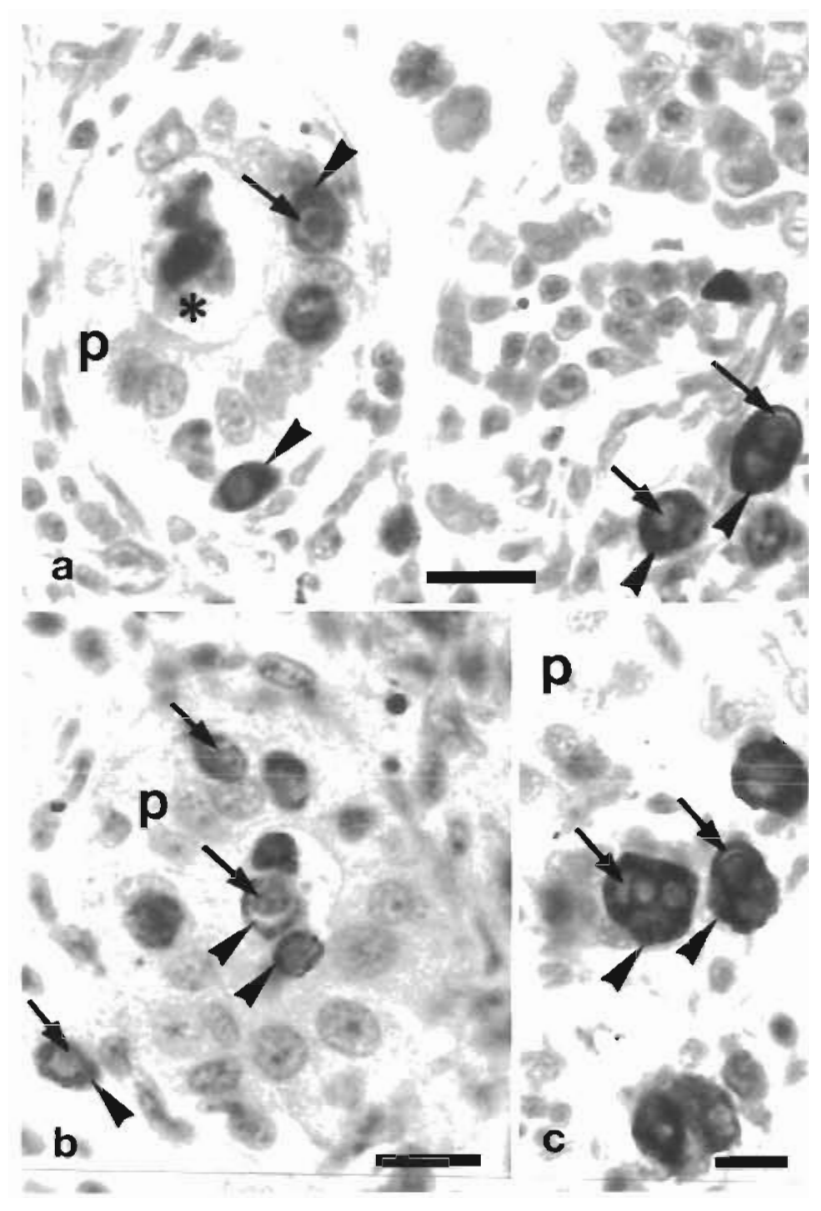

4 Fig. 7. Oncorhynchus mykiss. Kidney sections of trout undergoing experimental $\mathrm{PKD}$ probed with different $\mathrm{Abs}$ and stained by immunoperoxidase and amino-ethyl-carbazole (AEC). The antigenicity of PKX cells is restricted to primary cells. Bar scale $=20 \mu \mathrm{m}$. (a) Treatment by a pool of MAbs: the parasite cells are present in the lumen and epithelium of second segment proximal tube ( $p$ ) and interstitium, primary cell (arrowhead), daughter cells (arrow), sporoblast (asterisk). (b) Treatment by MAb 10. (c) Treatment by absorbed rabbit serum

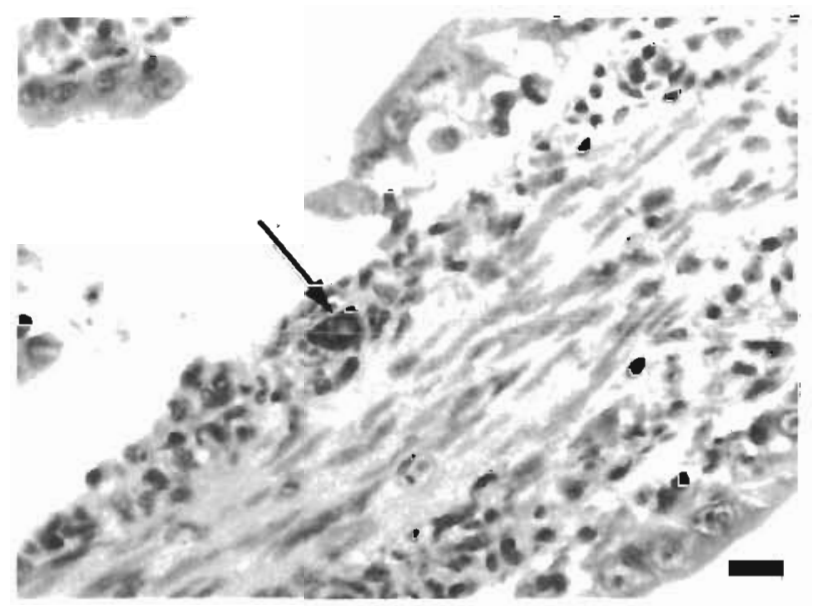

Fig. 8. Oncorhynchus mykiss. Ascending intestine of trout undergoing PKD as in Fig. 7. PKX cells stained by AEC (arrow) in the mucosa. Scale bar $=20 \mu \mathrm{m}$
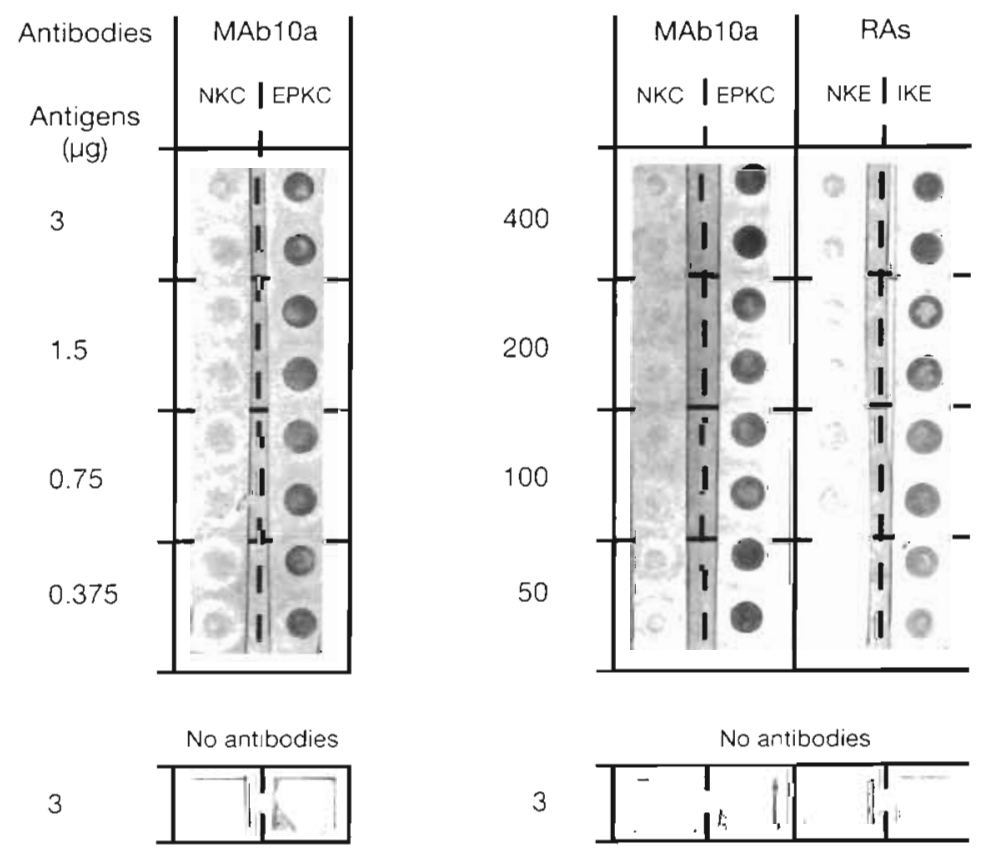

Fig. 9. Antigenicity of EPKC and PKX-infected kidney extracts (IKE) for homologous rabbit serum and mouse MAbs. Membrane was dotted with various amounts of EPKC Ag and NKC Ag $(0.375$ to $3 \mu \mathrm{g}$ in $100 \mu \mathrm{l}$ of buffer) and with NKE $\mathrm{Ag}$ and IKE Ag (50 to $400 \mu \mathrm{g}$ in $100 \mu \mathrm{l}$ of buffer). Immunological staining was made with MAb 10a (pure hybridoma supernatant) or an in vivo absorbed homologous rabbit serum (RAs) 
myxosporeans present in kidney tissue of the nonsalmonid fish belonging to 9 species captured in the vicinity of 2 farms where PKD was found. Antigenicity testing was conducted simultaneously with RAs. Although developmental stages (including spores) of Myxobolus sp., Myxidium sp. and Sphaerospora sp. were detected in fresh mounts or histological sections of kidney, no crossed antigenicity with that of PKX cell was detected.

\section{Antigenicity of crude extracts of PKX-infected rainbow trout tissues}

The immunodot blotting of crude PKX-infected kidney extracts (IKE) was run in parallel with that of EPKC $\mathrm{Ag}$ and NKC Ag. The dots were probed with RAs and those MAbs that responded in ELISA. EPKC Ag and IKE reacted positively with RAs and MAbs 8 and 10 at all protein amounts tested whereas the negative controls NKC and NKE (normal kidney extracts) antigens did not (Fig. 9).

\section{Protein patterns of EPKC and antigenicity of reduced parasitic proteins}

Application of 2-mercaptoethanol-reduced EPKC Ag and NKC Ag to a $12 \%$ polyacrylamide gel allowed the visualization of several protein bands unique to EPKC Ag. The most conspicuous of these bands exhibited relative mobility values of $55,49,42$ and $32 \mathrm{kDa}$ respectively (Fig. 10). The antigenicity of the EPKC was further studied with Western blot techniques.

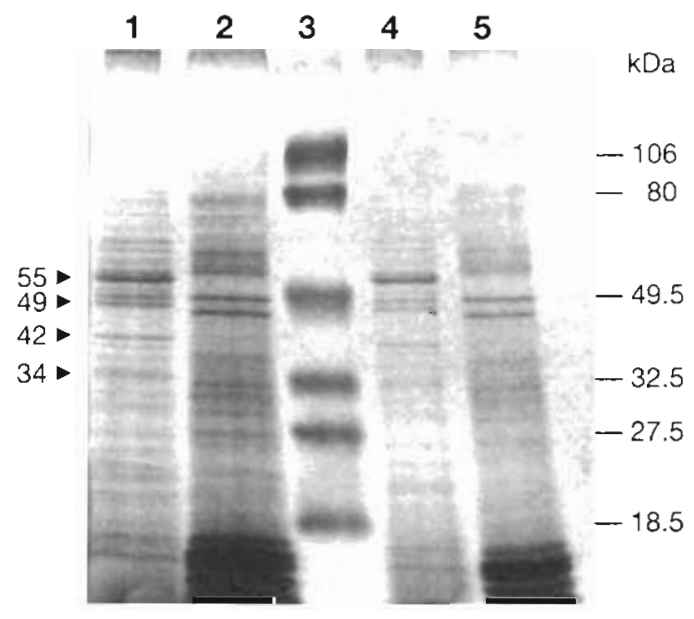

Fig. 10. Electrophoretic (SDS- PAGE) profiles of EPKC antigen and NKC antigen after Coomassie Brillant Blue staining. Lane 1, EPKC $20 \mu \mathrm{g}$; lane 2, NKC $20 \mu \mathrm{g}$; lane 3, molecular weight markers; lane 4. EPKC $10 \mu g$; lane 5, NKC $10 \mu \mathrm{g}$

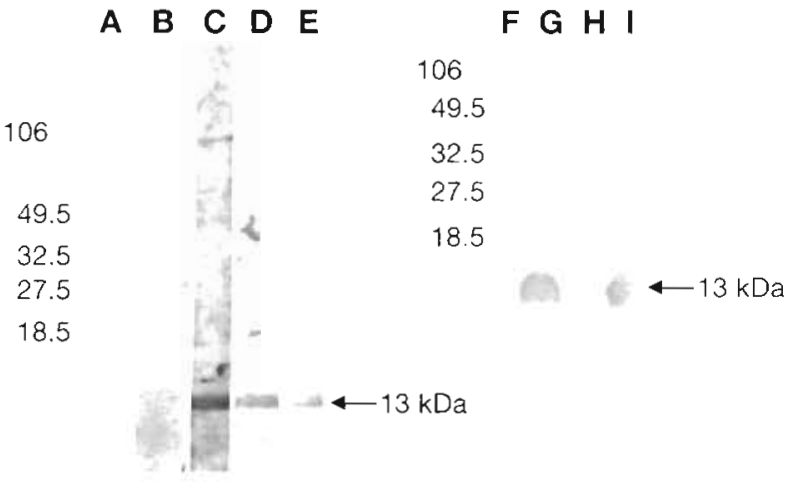

Fig. 11 Immunological detection of PKX protein bands by Western blot probed with RAs and MAbs. Proteins on strips A to $E$ and $F$ to $I$ were separated on a $15-10 \%$ gel gradient and $15 \%$ gel respectively. Strips loading and probing: $\mathrm{A}, \mathrm{NKC}+$ MAb 10a; B,EPKC + MAb 2a; C, EPKC + RAs; D,EPKC + MAb 10ai E, EPKC + MAb 8a; F, NKC + RAs; G, EPKC + RAs; $\mathrm{H}, \mathrm{NKC}+\mathrm{MAb} 10 \mathrm{a}_{i} \mathrm{I}$, EPKC + MAb 10a. Relative mobility markers in $\mathrm{kDa}$ are the numbers (18.5 to 106) placed at the left of each strip group. Arrows at the right indicates the PKX $13 \mathrm{kDa}$ immunoreactive protein

After electrotransfer onto membrane and immunological probing, only 1 protein band, with a relative mobility of $13 \mathrm{kDa}$, was recognized by RAs and MAbs 8 and 10 (Fig. 11)

\section{DISCUSSION}

The antigenic study presented here starts with the production of rabbit and mouse MAbs after immunization with PKX antigenic material obtained by a novel concentration technique developed as part of the study. Our investigations result in the demonstration of one $13 \mathrm{kDa}$ parasitic protein that bears a linear epitope present on the PKX cell membrane and provide evidence for the existence of 3 other epitopes, one of them likely being conformational. All antigenicity detected lies in the primary cell and is strictly specific for PKX insofar as no cross reaction with host tissue or developmental stages of myxosporeans from 3 genera were observed. The antigenic preparation, EPKC Ag, which seems to be free of trout Igs, allows detection of the humoral response of trout to PKD in ELISA without hindrances due to high reactivities of the background Ag. Several original results, such as PKX concentration technique, immunodot blotting of PKX-infected tissue samples, parasitic protein pattern, 13 kDa parasitic protein and parasitic epitopes, humoral response of trout to PKD, are reported in this study. Additionally, the development of novel immunological probes for PKX was an outcome of this work 
The PKX cell enrichment technique used is a modification of a procedure formerly used by R. Hedrick (unpubl.). It consists of incubating the PKX-infected kidney in cell culture medium for 16 to $18 \mathrm{~h}$ at $14^{\circ} \mathrm{C}$, thus facilitating detachment of inflammatory cells from parasites, before undertaking the dissociation of kidney tissue. The ratio of parasitic cells obtained in these suspensions is consistently $\geq 50 \%$ and thus higher than that of the original technique. Similarly our parasite concentration method appears to be preferable to immunomagnetism used by other authors (Adams \& Morris 1994) which suffers from reproducibility (A. Adams pers. comm.) and also because our technique can be completed prior to any development of Abs.

Both rabbit antisera and MAbs produced in this work strengthen the panel of arailable PKX-specific biologics that were previously represented only by GS-1 lectin (Castagnaro et al. 1991) and MAb B12 (Adams et al. 1992). Our present state of knowledge on PKX antigens is limited to that which is known about myxosporeans in general, for which only 2 biologics, a rabbit antiserum against Myxobolus cerebralis (Hamilton \& Canning 1988) and a MAb to Ceratomyxa shasta (Bartholomew et al. 1989), are currently available.

The parasitic Ag derived from the above PKX cell suspension contains soluble proteins of parasitic origin, as shown by SDS-PAGE, that are fairly immunogenic for rabbit and mouse after intradermal delivery. It is likely that the foot pad immunization of mice followed by cell fusions performed using poplietal nodes accounted for a satisfactory number of relevant hybridomas obtained, compared to that resulting from the protocol comprising intraperitoneal immunizations and fusion with splenic cells.

Although it is not pure parasitic material, the PKX Ag preparation (EPKC Ag) was well suited for a clear demonstration of a trout Ab-mediated response to PKX by ELISA. The quality of this Ag allowed us to overcome binding due to the high background reactivity of fish Ig in response to PKX reported in a review using immunofluorescence (Hedrick et al. 1993) but never confirmed since. Indeed, the PKX cells in kidney imprints used as Ag already bore Abs, which limited the detection of Abs in sera tested by IF or ELISA. The use of skim milk instead of BSA as a blocking agent for ELISA may also have contributed to the success of detecting the humoral immune response detection insofar as it avoids the binding of natural Abs (Gonzales et al. 1988).

Our Abs appear to be strictly specific to PKX since no reactivity was detected with fish tissues. This was aided by the in vivo absorption technique with rabbit sera and the selection protocol for Ab secreting hybridomas. Parasitic antigens detected were of the PKX primary cells as shown by immunohistochemistry and, to a lesser extent, by IF with live or PF-fixed PKX cells. Thus antigens of soluble proteins act as strong immunogens in the EPKC preparations and are easily released by grinding of the $\mathrm{PKX}$-infected kidney tissues. They can then be detected by immunodot blotting of supernatants from homogenate. The immunodot blot technique for PKX is worthy of further development because it may offer a convenient procedure for monitoring the course of both experimental and natural PKD. In contrast, ELISA, which was excellent using EPKC Ag, failed to detect PKX antigenicity in crude infected kidney extracts. Several causes could account for this failure. The relevant Ag could be masked by blood components or immunocomplexes during coating. The concentration of PKX Ag available for detection in crude kidney extracts is presumably lower that in EPKC Ag. For this reason the dot immunobinding assay could display a higher sensitivity to PKX Ag in crude extracts than analogous ELISA as previously reported with other materials (Gordon et al. 1983). Indeed, due to their porous structure, the dot membranes allow high surface density of $\mathrm{Ag}$ and further concentration on dots of large volumes of Abs, followed by enzymatic staining concentrated in small volumes of dot. In contrast, in microplate ELISA, the Ag presents a low surface density on plastic and is revealed by Abs distributed on a large area and a staining reaction distributed in a whole volume of liquid (Gordon et al. 1983).

The $\mathrm{Ab}$ specificity is restricted to $\mathrm{PKX}$ cell stages thus far. Indeed parasitic stages that resembled spores were found in a section of kidney tissue from 1 trout after staining with haematoxylin and eosin, but in replicate section further treated with polyclonal or monoclonal Abs these spore-like stages failed to react. This may be substantiated by the fact that spores do not derive from primary cells but from a daughter cell that has probably undergone an antigenic shift, whereas our Abs were prepared using Ag of primary cell origin. Similar findings were previously obtained for PKX (Adams et al. 1992) and Ceratomyxe shasta, for which the MAb produced using trophozoites as immunogens did not react with spores (Bartholomew et al. 1989).

Initial immunohistochemical screening of myxosporean-infected non-salmonid fish kidney tissues with our Abs did not show any cross antigenicity and enhanced the status of the PKX specificity of these Abs (including those present in rabbit sera). However, the above immunostaining tests only encompassed spores of the 3 myxosporean genera observed, formation sites of Myxobolus sp. spores in kidney interstitium and intra-luminal pre-sporal stages of Sphaerospora sp. Additional myxosporeans need to be examined to confirm our preliminary findings. 
In the same way that Abs from rabbit serum against Myxobolus cerebralis spores reacted with presporal stages of the parasite, our MAbs specific for Ag from PKX primary cell were able to recognize former parasitic stages, i.e. actinosporeans, that are involved in the life cycle of myxosporean parasites (Wolf \& Markiw 1984, El Matbouli et al. 1992). The immunological sreening of actinosporeans present in PKD-infected sites would be a next step in the investigation of the life cycle of PKX.

Among several parasitic proteins visualized by SDSPAGE (possibily different fragments of one same protein), only one with a relative mobility of $13 \mathrm{kDa}$ displayed antigenicity for rabbit Abs whereas the antigenicity of the other proteins visible in Fig. 10 seems to have undergone an irreversible destruction by SDS and mercaptoethanol (Gottstein 1983). The $13 \mathrm{kDa}$ protein bears an epitope, probably linear, recognized by MAbs 1, 6, 8 and 10, that withstands denaturing conditions. This epitope, localized on the parasitic cell surface, as demonstrated by membrane fluorescence with the above MAbs, is easily released into supernatants from infected tissue as detected by immunodot blot. This protein epitope likely constitutes a major component of the EPKC Ag. The external localization of this epitope on PKX cells suggests it could play an important role in the immune response of fish but this remains to be established.

The existence of at least 3 other epitopes is indicated by the reactivity of the panel of MAbs. The second epitope is recognized by those MAbs that do not react in ELISA or in Western blot but are positive in IF and histoimmunochemistry, i.e. MAbs 2, 5 and 11. The failure to react in ELISA and Western blot suggests a sensitivity of the epitope to coating and the existence of a conformational epitope, respectively. The cytoplasmic location of this epitope as shown by fluorescence seems to be localized more deeply in primary cells than the first epitope. Nevertheless, the negative ELISA response does not appear to be caused by a low Ig content of hybridoma culture fluids since even ascitic fluids from MAb 11, which represent an IF titre of 20000, were always negative in ELISA. The third epitope is only revealed in IF by MAbs 4 and 7 and was not detected by immunohistochemistry. The fourth epitope, defined by MAbs 3 and 9, was revealed by ELISA and immunohistochemistry and faintly in Western blot with MAb 3. The lack of reactivity in IF could be due by the masking of the epitope in the imprints used in this test. In our hands, MAb B12 from Adams et al. (1992), which is also specific for an epitope present in primary cell, gave positive results in ELISA, IF and immunohistochemistry but not in Western blot. It thus may probe an epitope different from those we have described above.
Whether or not the MAbs that tentatively define putative epitopes on the PKX cell can compete with each other remains unknown but a simple examination of Table 2 suggests that MAbs $8 \& 10,4 \& 7$, and $3 \& 9$ may be identically paired. The epitope localization at the ultrastructural level of PKX cell by immunogold staining as performed with Ceratomyxa shasta (Bartholomew et al. 1990) was attempted but failed, perhaps because of fixation problems. This part of the work will be completed in the near future.

This study has shown that PKX cells concentrated and further processed according to described protocols provide valuable immunogenic and antigenic material (EPKC Ag) suitable for creating a panel of immune sera and MAbs from rabbit and mouse respectively, and for examining both antigens of PKX and the $A b$ response of trout to $\mathrm{PKD}$. Our results demonstrate that a principal parasitic protein of $13 \mathrm{kDa}$ bearing a linear epitope is located on the PKX cell membrane. In addition, at least 3 other putative epitopes are found on the primary parasitic cell.

Through providing antigenic data, this study has generated immunological tools that are being used to advance knowledge on PKD at several levels including: immunology, by studying the Ab response of trout using EPKC Ag; epidemiology, by screening actinosporeans using MAbs; biochemistry, by purifying some EPKC Ag proteins using MAbs; cytology, by immunogold labelling of epitopes with MAbs; and molecular biology, by screening PKX expression libraries. This latter use of the MAbs is the subject of a report to be published separately.

Acknowledgements. The staff of the experimental Fish Facilities of INRA' Research Centre of Jouy-en-Josas is acknowledged for careful maintenance of experimental groups of fish throughout this work. We are indebted to T. Delaunay for skillful contributions and advice in mice immunization, and achievement of 2 fusions that generated our hybridomas. We thank Mrs B. Faivre and D. Monge for efficient technical assistance and Mrs I. Clement for the preparation of the manuscript. We also thank the staff of Conseil Superieur de la Pêche at Compiègne for electro-fishing capture of nonsalmonid fish. Research was supported by the European Community (contract AIR2CT93-1570) and Sanofi Santé Nutrition Animale.

\section{LITERATURE CITED}

Adams A, Morris D (1994) Purification of cells using immunomagnetism. In: Stolen JS, Fletcher SL, Rowley AF (eds) Techniques in fish immunology. SOS Publications, Fair Haven, NJ, p 23-26

Adams A, Richards RH, Marin de Mateo M (1992) Development of monoclonal antibodies to PKX, the causative agent of proliferative kidney disease. J Fish Dis 15 : $515-521$

Bartholomew JL, Rohovec JS, Fryer JL (1989) Development, characterization, and use of monoclonal and polyclonal 
antibodies against the Myxosporean, Ceratomyxa shasta. J Protozonl 36(4):397-401

Bartholomew JL, Yamamoto T, Rohovec JS, Fryer JL (1990) Immunohistochemical characterization of a monoclonal antibody against Ceratomyxa shasta. J Aquat Anim. Health 2:68-71

Bradford MM (1976) A rapid and sensitive method for the quantification of microgram quantities of proteins utilizing the principle of protein-dye binding. Analyt Biochem 72: $248-254$

Castagnaro M, Marin M, Ghittino C, Hedrick RP (1991) Lectin histochemistry and ultrastructure of rainbow trout Oncorhynchus mykiss kidneys affected by proliferative kidney disease. Dis Aquat Org 10:173-183

Clifton-Hadley RS, Bucke D, Richards RH (1987) A study of the sequential clinical and pathological changes during proliferative kidney disease in rainbow trout, Salmo gairdneri Richardson. J Fish Dis 10:335-352

DeLuca D, Wilson M, Warr GW (1983) Lymphocytes heterogeneity in the trout, Salmo gairdneri, defined with monoclonal antibodies to IgM. Eur J Immunol 13:546-551

D'Silva J, Mulcahy MF, de Kinkelin P (1984) Experimental transmission of proliferative kidney disease in rainbow trout, Salmo gairdneri Richardson. I Fish Dis 7:235-239

El-Matbouli M, Fisher-Scherl T, Hoffmann RW (1992) Present knowledge on the life cycle, taxonomy, pathology, and therapy of some Myxosporea spp. important for fresh water fish. In: Faisal M, Hetrick F (eds) Annual review of fish diseases, Vol II. Pergamon Press, New York, p 367-402

Ferguson HW, Adair B (1977) Protozoa associated with proliferative kidney diseases in rainbow trout, Salmo gairdneri. Vet Rec 100:158-159

Foott JS, Hedrick RP (1987) Seasonal occurence of the infectious stage of proliferative kidney disease (PKD) and resistance of rainbow trout, Salmo gairdneri Richardson, to reinfection. $J$ Fish Biol 30:477-484

Gonzales R, Charlemagne J, Makana W, Avrameas S (1988) Specificity of natural serum antibodies present in phylogenetically distinct fish species. Immunol 63:31-36

Gordon J. Hawkes R, Niday E, Rordorf C, Rosenthal M, Towbin $H$ (1983) Dot immunobinding and western blot as diagnostic tools. In: Avrameas $S$, Druet $P$, Masseyeff $R$, Feldmann G (eds) Developments in immunology, Vol XVIII. Elsevier Science Publishers, Amsterdam, p 303-306

Gottstein B (1983) Isolation of an antigen from Echinococcus multilocularis with high species specificity in ELISA and

Responsible Subject Editor: W. Körting, Hannover, Germany its identification with the western blot technique. In: Avrameas S, Druet P, Masseyeff R, Feldmann G (eds) Developments in immunology, Vol XVIII. Elsevier Science Publıshers, Amsterdam, p 299-302

Hamilton AJ, Canning EU (1988) The production of mouse anti-Myxosoma cerebralis antiserum from Percoll ${ }^{\mathrm{R}}$-purifled spores and its use in immunofluorescent labelling of Historesin ${ }^{R}$-embedded cartilage derived from infected rainbow trout, Salmo gairdneri Richardson. J Fish Dis 11: $185-190$

Hawkes R, Niday E, Gordon J (1982). A dot-immunobinding assay for monoclonal and other antibodies. Analyt Biochem 119:142-147

Hedrick RP, MacConnell E, de Kinkelin P (1993) Proliferative kidney disease of salmonid fish. In: Faisal $M_{1}$ Hetrick $F$ (eds) Annual review of fish diseases, Vol III. Pergamon Press, New York, p 277-290

Kent ML, Hedrick RP (1985) PKX, the causative agent of proliferative kidney disease (PKD) in Pacific salmonid fishes and its affinities with the Myxozod. J Protozool 32:254-260

Kent ML, Hedrick RP (1986) Development of the PKX myxosporean in rainbow trout Salmo gairdneri. Dis Aquat Org $1: 169-182$

Köhler G, Milstein C (1975) Continuous cultures of fused cells secreting antibodies of predefined specificity. Nature 256 : $495-497$

Laemmli UK (1970) Cleavage of structural protein during the assembly of the head of bacteriophage T4. Nature 227 . $680-685$

MacConnel] E, Smith CE, Hedrick RP, Speer CA (1989) Cellular inflammatory response of rainbow trout to the protozoon parasite that causes proliferative kidney disease. $\mathrm{J}$ Aquat Anim Health 1:108-118

Marin de Mateo $M$, Adams A, Richards RH, Castagnaro $M$, Hedrick RP (1993) Monoclonal antibodies and lectin probes recognize developmental and sporogonic stages of $\mathrm{PKX}$, the causative agent of proliferative kidney disease in European and North American fish. Dis Aquat Org 1.5: $23-29$

Voronin VN (1993) PKX like organism in common carp dunng swimbladder inflammation: further evidence of an association with the myxosporean Sphaerospora renicola. Bull Eur Ass Fish Pathol 13(4):127-129

Wolf K, Markiw M (1984) Biology contravenes taxonomy in the Myxozoa: new discoveries show alternation of invertebrate and vertebrate hosts. Science 225:1449-1452

Manuscript first received: February 1, 1996

Revised version accepted: May 28, 1996 